DOI: 10.4274/ejgg.galenos.2019.82

Eur J Geriatr Gerontol 2019;1(2):43-45

\title{
Putting Sarcopenia at the Forefront of Clinical Practice
}

\author{
(1) Gülistan Bahat ${ }^{1}$, (1) Alfonso Cruz-Jentoft ${ }^{2}$ \\ 1 İstanbul University Faculty of Medicine, Department of Internal Medicine, Division of Geriatrics, Istanbul, Turkey \\ 2Ramón y Cajal University Hospital, Clinic of Geriatrics, Madrid, Spain
}

Sarcopenia is becoming one of the major hot topics in the care of older persons. In recent years, many different international consensus groups have proposed different consensus definitions (1-4). Among them, the European Working Group on Sarcopenia in Older People (EWGSOP) consensus definition, which was published on 2010, comes forward as being the most cited and recognized definition in the literature. In the late 2018, considering the accumulating scientific evidence and experience in applying sarcopenia in clinical practice, an update was deemed necessary and EWGSOP published the revised consensus on definition and diagnosis of sarcopenia (EWGSOP2) (5). The major stated aim of this document is to try to foster the introduction of sarcopenia in usual clinical practice.

EWGSOP2 aims to increase consistency of research designs, clinical diagnoses and consequently the care for people with sarcopenia. As a rapid view, sarcopenia is considered as a muscle disease (muscle failure) rooted in adverse muscle changes that occur and accumulate across the lifetime. EWGSOP2 focuses on low muscle strength as a key characteristic of sarcopenia. It suggests detection of low muscle quantity and quality to confirm the sarcopenia diagnosis, and identifies poor physical performance as indicative of severe sarcopenia. Accordingly, EWGSOP2 updated the clinical algorithm to be used for sarcopenia case finding, assessment, confirmation and severity determination (Figure). Lastly, EWGSOP2 provided clear cutoff points for measurements of variables that identify and characterise sarcopenia when available.

In clinical practice, EWGSOP2 advises using the SARC-F screening questionnaire to find individuals with probable sarcopenia. Use of grip strength and chair stand measures are advised to identify low muscle strength. To generate evidence that confirms muscle of low quantity or quality, evaluation of muscle by dual-energy
X-ray absorptiometry (DXA) and bio-electrical impedance analysis (BIA) methods in usual clinical care, and by DXA, MRI or CT in research and in specialty care for individuals at high

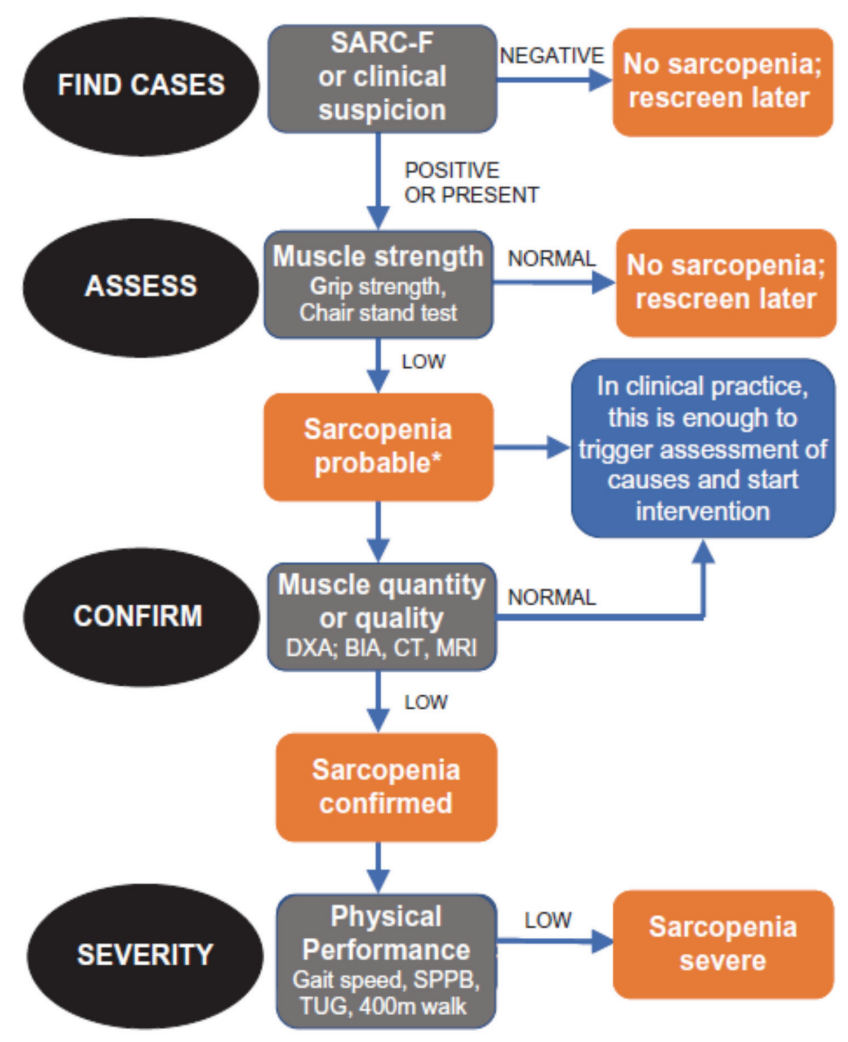

Figure. EWGSOP2 algorithm for case-finding, making a diagnosis and quantifying severity of sarcopenia in practice.

${ }^{*}$ Consider other reasons for low muscle strength (e.g. depression, sroke, balance disorders, peripheral vascular disorders).

Reproduced by permission from Cruz-Jentoft AJ, et al. Sarcopenia: revised European consensus on definition and diagnosis. Age Ageing 2019;48:16-31.

Address for Correspondence: Gülistan Bahat, İstanbul University Faculty of Medicine, Department of Internal Medicine, Division of Geriatrics, İstanbul, Turkey

Phone: +90 21241420 00-33204 E-mail: gbahatozturk@yahoo.com ORCID: orcid.org/0000-0001-5343-9795

Received: Jun 28, 2019 Accepted: Jul 09, 2019

Cite this article as: Bahat G, Cruz-Jentoft A. Putting Sarcopenia at the Forefront of Clinical Practice. Eur J Geriatr Gerontol 2019;1(2):43-45

๑Copyright 2019 by the Academic Geriatrics Society / European Journal of Geriatrics and Gerontology published by Galenos Publishing House. 
risk of adverse outcomes are recommended. The recommended measures of physical performance are SPPB, TUG and 400-m walk; these tests are advised to assess the severity of sarcopenia.

Some questions may arise during the application of the EWGSOP2 definition in clinical practice. We may propose some answers to these questions.

\section{1) Should I always use the SARC-F to find individuals with probable sarcopenia?}

As noted in the consensus paper, in clinical practice, case finding should start when a patient reports symptoms or signs of sarcopenia (i.e. falling, feeling weak, slow walking speed, difficulty rising from a chair or weight loss/muscle wasting). In such cases, further testing for sarcopenia is recommended and there is no need to use any screening questionnaire. EWGSOP2 recommends use of the SARC-F questionnaire $(6,7)$ as a way to elicit self-reports from patients on signs that are characteristic of sarcopenia and as a formal approach. Therefore, in clinical practice one should not feel be obliged to use SARC-F, except with screening purposes in high risk populations. Any symptom that may be related to sarcopenia should prompt the physician to look and assess for sarcopenia.

\section{2) Is it necessary to measure both the hand grip strength and chair stand test in the same patient in case measurement is possible?}

It is not necessary to use both hand grip strength and chair stand test for sarcopenia assessment. If the clinician can assess grip strength reliably, that is the reference to diagnose sarcopenia, to be consistent. It is advisable to use the chair stand test only when grip strength is unavailable or impractical.

\section{3) If I cannot measure dominant hand grip strength, should I measure grip strength in the non-dominant hand or change to the chair stand test?}

As hand grip is the preferred muscle strength measure, it is advisable to measure it in the non-dominant hand, before using the alternative test.

4) EWGSOP2 recommended some specific cut-offs but also recommended to use the normative data of the population when available. Cut-offs for total skeletal muscle mass and handgrip strength have been published for Turkish population. Which cutoffs shall I use?

This is particularly important in Turkish studies and it seems some uncertainty is present up to now in this regard. Cut-offs for total skeletal muscle mass and hand grip strength have been published for Turkish population (8).

Cut-off points depend on the measurement method and on the availability of reference studies in the particular populations. It has been observed that disputes over cut-off points have hampered research and development for sarcopenia field due to lack of study consistency up to EWGSOP2 consensus. That is why EWGSOP2 has opted to provide recommendations for cut-off points. These cut-offs were aimed to be simple and rounded figures so that they can be handled and implemented easily in clinical practice. Previously, the Asian Working Group on Sarcopenia developed a EWGSOP-based consensus that specified cut-off points for diagnostic variables (9). This approach proved to be very useful for implementation of sarcopenia care. Therefore, rather than the Turkish population specific cut-offs, we would suggest using the recommended cut-offs also for appendicular skeletal muscle mass and hand grip strength in the Turkish population. However, there is an important point here. EWGSOP2 recommended cut-offs only for the appendicular skeletal muscle mass, not the total skeletal muscle mass. Turkish reference study proposed cut-offs for total skeletal muscle mass. Many research centres do not have access to DXA and therefore may use total skeletal muscle mass assessed by BIA. Therefore, if a clinician assesses total skeletal muscle mass, not the appendicular muscle mass, then he/she can use documented Turkish total skeletal muscle mass index thresholds as $9.2 \mathrm{~kg} / \mathrm{m}^{2}$ and $7.4 \mathrm{~kg} / \mathrm{m}^{2}$ in males and females respectively. These figures are for skeletal muscle mass adjusted (indexed by) height ${ }^{2}\left(\mathrm{~m}^{2}\right)$. Low skeletal muscle mass index cutoffs have also been published for total skeletal muscle mass adjusted by body mass index or weight in Turkish population $(10,11)$. Last point is that, one can use these recommended total or appendicular skeletal muscle mass thresholds when the skeletal muscle mass is assessed either by DXA or BIA.

Sarcopenia is linked with adverse outcomes and can improve with exercise and nutrition interventions. (12) However, it is usually not detected, diagnosed or treated in usual clinical practice. Time has come when research on sarcopenia has to be transferred to patient care.

\section{Ethics}

Peer-review: Internally peer-reviewed.

\section{Authorship Contributions}

Concept: G.B., A.C.J., Design: G.B., A.C.J., Data Collection or Processing: G.B., A.C.J., Analysis or Interpretation: G.B., A.C.J., Literature Search: G.B., A.C.J., Writing: G.B., A.C.J.

Conflict of Interest: No conflict of interest was declared by the authors.

Financial Disclosure: The authors declared that this study received no financial support.

\section{References}

1. Cruz-Jentoft AJ, Baeyens JP, Bauer JM, Boirie $Y$, Cederholm T, Landi F, Martin FC, Michel JP, Rolland Y, Schneider SM, Topinková E, Vandewoude M, Zamboni M, European Working Group on Sarcopenia in Older People. 
Sarcopenia: European consensus on definition and diagnosis: report of the European working group on sarcopenia in older people. Age Ageing 2010;39:412-423.

2. Muscaritoli $M$, Anker SD, Argilés J, Aversa $Z$, Bauer JM, Biolo G, Boirie $Y$, Bosaeus I, Cederholm T, Costelli P, Fearon KC, Laviano A, Maggio $M$, Rossi Fanelli F, Schneider SM, Schols A, Sieber CC. Consensus definition of sarcopenia, cachexia and pre-cachexia: joint document elaborated by Special Interest Groups (SIG) "cachexia-anorexia in chronic wasting diseases" and "nutrition in geriatrics". Clin Nutr 2010;29:154-159.

3. Morley JE, Abbatecola AM, Argiles JM, Baracos V, Bauer J, Bhasin S, Cederholm T, Coats AJ, Cummings SR, Evans WJ, Fearon K, Ferrucci L, Fielding RA, Guralnik JM, Harris TB, Inui A, Kalantar-Zadeh K, Kirwan BA, Mantovani $G$, Muscaritoli $M$, Newman AB, Rossi-Fanelli $F$, Rosano GM, Roubenoff $R$, Schambelan M, Sokol GH, Storer TW, Vellas B, von Haehling S, Yeh SS, Anker SD; Society on Sarcopenia, Cachexia and Wasting Disorders Trialist Workshop. Sarcopenia with limited mobility: an international consensus. J Am Med Dir Assoc 2011;12:403-409.

4. Studenski SA, Peters KW, Alley DE, Cawthon PM, McLean RR, Harris TB, Ferrucci L, Guralnik JM, Fragala MS, Kenny AM, Kiel DP, Kritchevsky SB, Shardell MD, Dam $\Pi$, Vassileva MT. The FNIH sarcopenia project: rationale, study description, conference recommendations, and final estimates. J Gerontol A Biol Sci Med Sci 2014;69:547-558.

5. Cruz-Jentoft AJ, Bahat $G$, Bauer J, Boirie $Y$, Bruyère 0 , Cederholm T, Cooper C, Landi F, Rolland Y, Sayer AA, Schneider SM, Sieber CC, Topinkova E, Vandewoude M, Visser M, Zamboni M; Writing Group for the European Working Group on Sarcopenia in Older People 2 (EWGSOP2), and the Extended Group for EWGSOP2 . Sarcopenia: revised European consensus on definition and diagnosis. Age Ageing 2019;48:16-31.

6. Bahat G, Yilmaz O, Kılıç C, Oren MM, Karan MA. Performance of SARC-F in Regard to Sarcopenia efinitions, Muscle Mass and Functional Measures. J Nutr Health Aging 2018;22:898-903.
7. Malmstrom TK, Morley JE. SARC-F: a simple questionnaire to rapidly diagnose sarcopenia. J Am Med Dir Assoc 2013;14:531-532.

8. Bahat G, Tufan A, Tufan F, Kilic C, Akpinar TS, Kose M, Erten N, Karan MA, Cruz-Jentoft AJ. Cut-off points to identify sarcopenia according to EuropeanWorking Group on Sarcopenia in Older People (EWGSOP) definition. Clin Nutr 2016;35:1557-1563.

9. Chen LK, Liu LK, Woo J, Assantachai P, Auyeung TW, Bahyah KS, Chou MY Chen LY, Hsu PS, Krairit O, Lee JS, Lee WJ, Lee Y, Liang CK, Limpawattana P, Lin CS, Peng LN, Satake S, Suzuki T, Won CW, Wu CH, Wu SN, Zhang T, Zeng P, Akishita M, Arai H. Sarcopenia in Asia: consensus report of the Asian working group for sarcopenia. J Am Med Dir Assoc 2014;15:95-101.

10. Bahat G, Tufan A, Kilic C, Öztürk S, Akpinar TS, Kose M, Erten N, Karan MA, Cruz-Jentoft AJ. Cut-off points for weight and body mass index adjusted bioimpedance analysis measurements of muscle mass. Aging Clin Exp Res 2019;31:935-942.

11. Bahat G, Tufan A, Kilic C, Aydın T, Akpinar TS, Kose M, Erten N, Karan MA, Cruz-Jentoft AJ. Cut-off points for height, weight and body mass index adjusted bioimpedance analysis measurements of muscle mass with use of different threshold definitions. Aging Male 2018:1-6.

12. Dent E, Morley JE, Cruz-Jentoft AJ, Arai H, Kritchevsky SB, Guralnik J, Bauer JM, Pahor M, Clark BC, Cesari M, Ruiz J, Sieber CC, Aubertin-Leheudre M, Waters DL, Visvanathan R, Landi F, Villareal DT, Fielding R, Won CW, Theou O, Martin FC, Dong B, Woo J, Flicker L, Ferrucci L, Merchant RA, Cao L, Cederholm T, Ribeiro SML, Rodríguez-Mañas L, Anker SD, Lundy J, Gutiérrez Robledo LM, Bautmans I, Aprahamian I, Schols JMGA, Izquierdo M, Vellas B. International Clinical Practice Guidelines for Sarcopenia (ICFSR): Screening, Diagnosis and Management. J Nutr Health Aging 2018;22:1148-1161. 